\title{
Características Fonéticas, Processos Fonológicos e Morfofonológicos nas Oclusivas Velares Labializadas da Língua Guarani
}

Phonetic Characteristics, Phonological and Morphophonological Processes

in Labialized Velar Plosives of Guarani Language

Resumo. A língua Guarani é falada no Brasil, em diferentes Estados, pelas parcialidades Nhandeva, Kaiowá, Nhandewa e Mbyá. Este trabalho tem como objetivo apresentar características acústicas e articulatórias das oclusivas velares labializadas da língua Guarani, $/ \mathrm{k}^{\mathrm{w}} / \mathrm{e} / \mathrm{g}^{\mathrm{w}} /$, considerando-se processos envolvendo esses sons, tanto no nível fonológico como também no nível morfológico, a partir de dados de fala obtidos junto a falantes das quatro parcialidades Guarani do Brasil. Após caracterização fonética dos sons, apresenta-se, ao final, a proposta de que os fonemas labializados $/ \mathrm{k}^{\mathrm{w}} / \mathrm{e} / \mathrm{g}^{\mathrm{w}} /$ encaixam-se no jogo de oposições sistemáticas da língua Guarani, em seu nível fonológico: / $/ \mathrm{w}^{\mathrm{w}} /$ pertence à classe natural das obstruintes [-estridentes] e $/ \mathrm{g}^{\mathrm{w}} /$, à classe das soantes [-contínuas] e os processos que as envolvem demonstram que a harmonia nasal é operante e é coerente nos processos fonológicos e também nos processos morfofonológicos, tendo como objetivo final manter a oposição funcional do sistema que se dá entre obstruintes e soantes.

Palavras-chave: Língua Guarani; Fonética; Fonologia; Morfologia; Oclusivas Velares Labializadas.

\begin{abstract}
Guarani language is spoken in Brazil, in different states, by the partialities Nhandeva, Kaiowá, Nhandewa and Mbyá. This paper aims to present the acoustic and articulatory characteristics of the Guarani language labialized velar plosives: $/ \mathrm{k}^{\mathrm{w}} /$ and $/ \mathrm{g}^{\mathrm{w}} /$, considering phonological and morphological processes involving these sounds, from speech data obtained with speakers of the four Guarani partialities of Brazil. After the phonetic characterization of those sounds, we present, at the end, the proposal that the labialized velar plosives $/ \mathrm{k}^{\mathrm{w}} /$ and $/ \mathrm{g}^{\mathrm{w}} /$ fit the systematic oppositions of the Guarani language at its phonological level: $/ \mathrm{k}^{\mathrm{w}} /$ belongs to the obstruent [-strident] sound class and $/ \mathrm{g}^{\mathrm{w}} /$ to the sonorant [-continuous] sound class, and the processes that surround them demonstrate that the nasal harmony is operative and coherent in phonological processes and also in morphophonological processes, with the ultimate goal of maintaining the functional opposition of the system that occurs between obstruent and sonorants.
\end{abstract}

Keywords: Guarani Language; Phonetics. Phonology; Morphology; Labialized Velar Plosives.

\section{Introdução}

A língua Guarani é falada no leste da Bolívia (Guarani do Chaco ou Chiriguano, Tapiete), no norte da Argentina (Mbyá, Guarani do Chaco ou Chiriguano, Tapiete), no Paraguai (Avá-Guarani ou Chiripá, Paĩ-Tavyterã ou Kaiowá, Mbyá, Guarani Paraguaio, Aché ou Guayaki) e no Brasil (Avá-Guarani ou Nhandeva, Kaiowá, Nhandewa e Mbyá).

Segundo Melià (1992, p. 245), os Avá Katú Eté, localizados no Brasil e no Paraguai, são descendentes prováveis dos Guarani do Guairá e do Mbaracajú. Esse grupo tem recebido, ao longo dos anos, diferentes denominações, como Chiripá e Avá-Guaraní, além das denominações da literatura etnográfica: Apapokúva, Oguauíva, Tañyguá e Cheirú. Um termo muito comum utilizado para esse grupo é o Nhandeva, que embora seja uma autodenominação para todos os grupos 
guarani ${ }^{1}$, é usado, preferencialmente para este grupo. O emprego do termo Nhandeva $^{2}$ para designar essa parcialidade foi utilizado também por Egon Schaden (1974), que preferiu grafá-lo à moda do espanhol, Ñandeva:

Ñandeva é autodenominação de todos os Guaraní... é a única autodenominação usada pelas comunidades que falam o dialeto registrado por Nimuendajú com o nome Apapokúva e que parece ter sido falado também pelos Tañyguá e algumas outras hordas mencionadas por aquele autor. Proponho, por isso, que se reserve o nome Ñhandeva para essa subdivisão. Pelos Mbüa é apelidada de Txiripá í, “os Txiripazinhos” (SCHADEN, 1974, p. 2)

Sob essa denominação, Schaden (1974) reuniu grupos locais habitantes do Estado de São Paulo e do Mato Grosso, sem fazer referência aos estados sulinos, tendo feito apenas uma ligeira menção a Txiripá nas margens do Paraná, "diferentes dos Txiripá i (Ñandeva)" (obra citada, p. 3-4). No entanto, por exclusão, antropólogos, indigenistas e linguistas "classificam" como Nhandeva toda comunidade de fala Guarani no Sul do Brasil, que não se identifique ou não possa ser identificada com os Mbyá.

Costa (2010), no entanto, ao considerar a história de migrações que, por um lado, separaram os grupos de fala guarani migrados da fronteira Brasil Paraguai (no atual Mato Grosso do Sul) daqueles que permaneceram naquela região e, por outro lado, causaram miscigenação entre os sobreviventes de parcialidades ou sub-parcialidades distintas, justificou a validade de distinguir, na "macro-parcialidade" Ñandeva, de Schaden (1974), pelo menos duas distintas sub-parcialidades: os Nhandeva que permaneceram no Mato Grosso do Sul (possivelmente com elementos em comum com grupos Avá-Guarani do Paraguai e no Oeste do Paraná) e os Nhandewa de São Paulo e do Norte do Paraná, aparentados entre si, e oriundos das mesmas migrações descritas por Curt Nimuendajú. ${ }^{3}$ A distinção introduzida por Costa (2010), lança mão das diferentes ortografias que os respectivos grupos utilizam, permitindo distinguir os do MS pela grafia com "v", daqueles de São Paulo e Norte do Paraná, pela grafia com "w". Essa distinção é adotada neste trabalho.

Os Nhandeva habitam predominantemente no Mato Grosso do Sul, embora algumas famílias sejam localizadas em outras regiões do Brasil. No Mato Grosso do Sul é comum a auto-denominação 'Guarani' para esse grupo, sendo também assim nomeados pelos Guarani-Kaiowá.

Os chamados Mbyá foram localizados tradicionalmente nos altos bosques da bacia do médio Paraná, no antigo Tarumá, Caaguasú e Guairá, tendo migrado para a costa atlântica, estão atualmente em todos os Estados do sul do Brasil, em São Paulo, Rio de Janeiro e Espírito Santo. Segundo Melià (1992, p. 249), os Mbyá dispersos pelo Paraguay, em Misiones, na Argentina, e no Brasil, apresentam grande unidade cultural, que as antigas migrações apenas têm modificado. Para ele (cf. Melià, 1992, p. 248), os Mbyá são os que mais se mantiveram distantes do processo colonial, não apenas por terem habitado lugares mais remotos, mas por sua ideologia de rejeição aos "outros". "Hasta hace muy pocos años podía ser considerado este pueblo indígena uno de los más herméticos del continente".

\footnotetext{
${ }^{1}$ Neste trabalho, são adotadas as normas propostas pela Associação Brasileira de Antropologia (ABA), que dispensa as flexões de gênero e número nos etnônimos.

${ }^{2} O$ termo pode ser compreendido como: [nã'n de] 'nós, nosso' + $\{v a ' \varepsilon\}$ 'nominalizador', 'quem somos', 'o que somos', 'o que é nosso'.

${ }^{3}$ Nimuendajú ([1912] 1987, p. 3-16) mencionou três grupos que migraram para o Estado de São Paulo (via Norte do Paraná): Apapocuva, Tañyguá e Oguauíva.
} 
Schaden (1974, p. 3) apresenta alguns termos utilizados para esse grupo:

\begin{abstract}
Mbüa ("gente") é a autodenominação mais usada pelos Guarani conhecidos na bibliografia como Kainguá, Kaiuá etc. e a que os Ñandeva chamam Tambéaópé ("chiripá largo") ou Txeirũ, Ñaneirũ ("meus ou nossos amigos"). Não raro, encontra-se também para estes índios a denominação Apütere, ou seja, apyteré (corrutelas: Apuiteré, Apiteré), que eles próprios, no entanto, repelem como depreciativo. Entre os paraguaios são conhecidos pelo apelido de Baticolas, em atenção ao Chiripá que usam entre as pernas. Também se ouvem outros subgrupos o apodo Aváhuguai, "homens de cauda", dado pelo mesmo motivo.
\end{abstract}

Para Melià (1992, p. 247), os Paĩ-Tavyterã podem ser identificados com os antigos itatins, que ocupavam a margem esquerda do rio Paraguai. O estudioso explica a conexão ao aspecto religioso: paĩ seria o título com que os deuses e moradores do paraíso saúdam e se dirigem a palavra, e tavyterã, os futuros habitantes da morada no centro da terra. Além do nome paĩ-tavyterã, são também conhecidos pelos termos genéricos Ava (pessoa indígena) e Te'ỹi (os da linhagem), localizados predominantemente no Mato Groso do Sul, embora algumas famílias morem em outras regiões do Brasil.

Identificar e distinguir as parcialidades Guarani sempre foi um tema complexo para os etnólogos, como para os indigenistas, pelas questões relacionadas à auto-identificação, pela mobilidade dos grupos, relações de casamento entre si etc. Até hoje, no Brasil, há muita confusão sobre as nomenclaturas das parcialidades Guarani, e não acredito que seja algo de simples resolução, sendo, em algumas regiões do Brasil, senão em todas, chamados simplesmente de 'Guarani'.

Considerando-se dados de fala obtidos junto a falantes das quatro parcialidades, este trabalho tem como objetivo apresentar características fonéticas das oclusivas labializadas da língua Guarani e, também, processos fonológicos e morfológicos que envolvem esses sons.

\title{
2. Características fonéticas das oclusivas velares labializadas da língua Guarani
}

As quatro parcialidades Guarani: Nhandewa, Mbyá, Kaiowá e Nhandeva, contrastam duas oclusivas velares labializadas $\left[\mathrm{k}^{\mathrm{w}}\right]$ e $\left[\mathrm{g}^{\mathrm{w}}\right]$. Conforme esclarecem Ladefoged e Maddieson (1996, p. 356), na maioria dos casos, o arredondamento dos lábios é produzido como uma articulação secundária, ocorrendo, conjuntamente, a subida da parte posterior da língua, ou seja, um gesto de velarização. Acusticamente, é possível verificar a transição da aproximante labiovelar [w] que se produz por meio de um movimento ascendente de F2, que ocorre no momento da soltura da oclusiva, como é comum em segmentos envolvendo sons labiovelares iniciais, nos quais, acusticamente há um alto grau de abaixamento de F2 (cf. ELLÍAS-ULLOÁ, 2010, p. 88).

Na figura a seguir, apresenta-se um exemplo da produção de [ $\left.\mathrm{k}^{\mathrm{w}}\right]$ em posição intervocálica, na palavra [ta'kwa] 'taquara', por um homem Mbyá, do Rio de Janeiro, por meio da qual é possível observar a transição de F2, da labializada, à vogal [a] seguinte: 
Figura 1: [ta'kwa] 'taquara' (Mbyá)

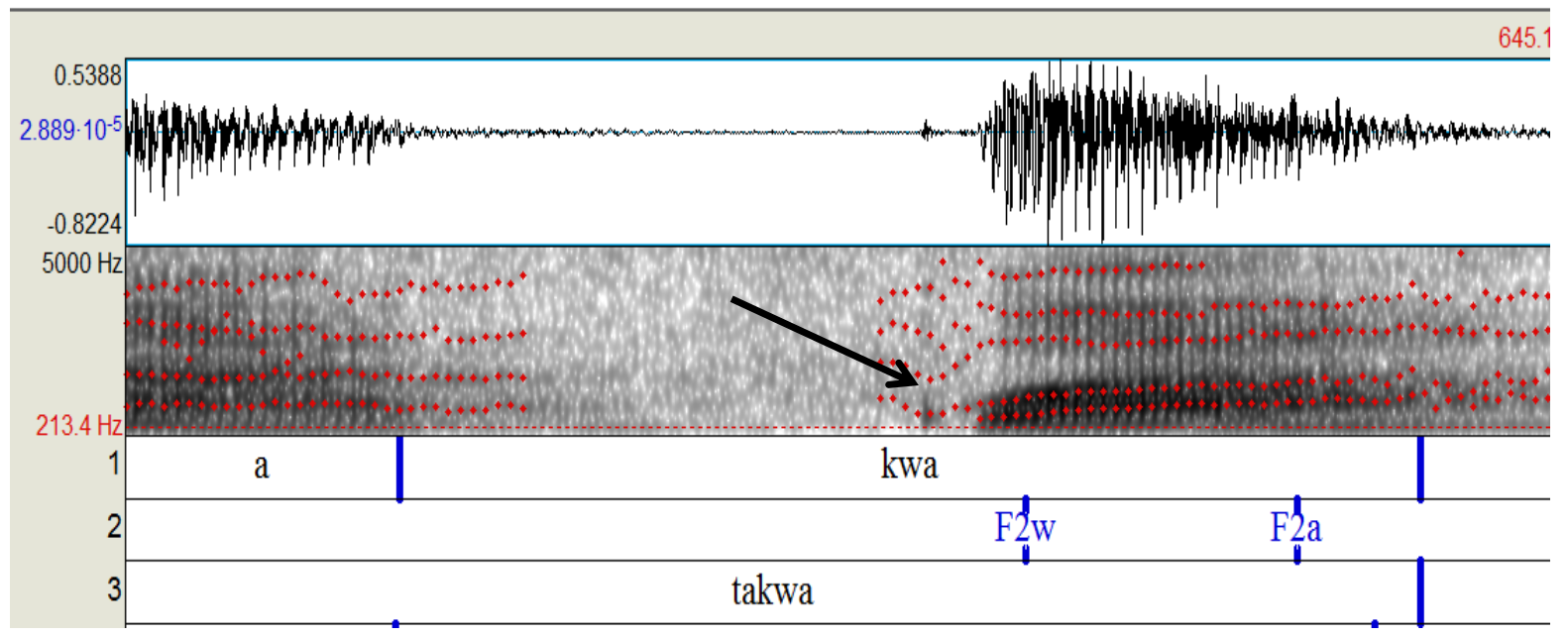

Fonte: própria autora

Na produção acima, o valor de F2, na porção inicial da aproximante [w], no ponto indicado na figura, é de $948 \mathrm{~Hz}$ e o F2 da vogal, no ponto indicado, de $1376 \mathrm{~Hz}$, o que confirma o abaixamento de F2.

Foneticamente, a distinção entre $\left[\mathrm{k}^{\mathrm{w}}\right]$ e a sequência $[\mathrm{ku}]$ é que, enquanto o fone $\left[\mathrm{k}^{\mathrm{w}}\right]+$ vogal é produzido em um mesmo impulso expiratório, na sequência $[k]+[\mathbf{u}]+$ vogal, a vogal $[u]$ tem seu impulso respiratório particular. Desconhecemos, no Guarani, a sequência $\mathbf{k}+/ \mathbf{u} /+$ vogal, pelo menos, em nossos dados de campo, esse dado não é verificado. Apresentamos, no entanto, um dado com a sequência $\mathbf{k}+/ \mathbf{u} /+/ \mathbf{l} /$ + /i/, da palavra [ava,tsiku'?i] 'fubá', por um homem do Rio de Janeiro, apenas para demonstrar um caso em que [u], após a oclusiva velar [k], tem seu impulso respiratório particular:

Figura 2: [ava,tsiku'?i] 'fubá' (Mbyá)

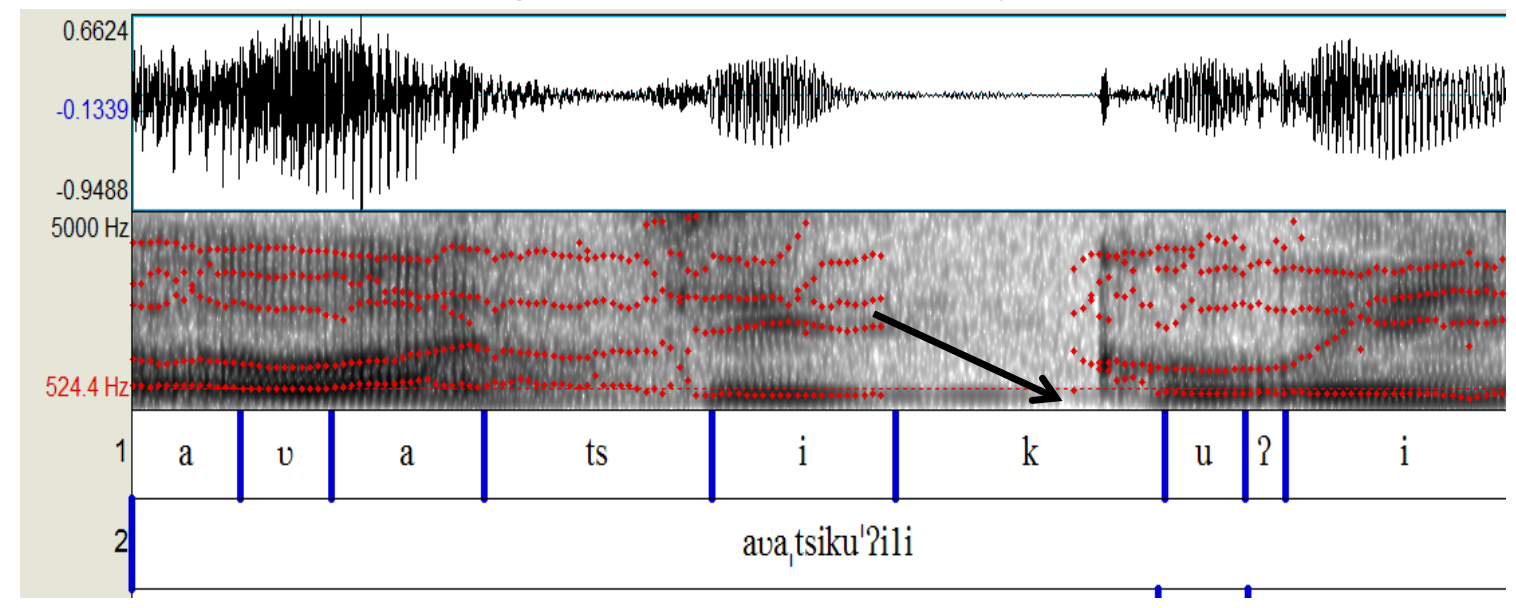

Fonte: própria autora

Abaixo, a produção da labializada vozeada [ $\left.\mathrm{g}^{\mathrm{w}}\right]$, em posição intervocálica, por um Mbyá do Rio de Janeiro: 
Figura 3: [tagª'to] 'gavião' (Mbyá)

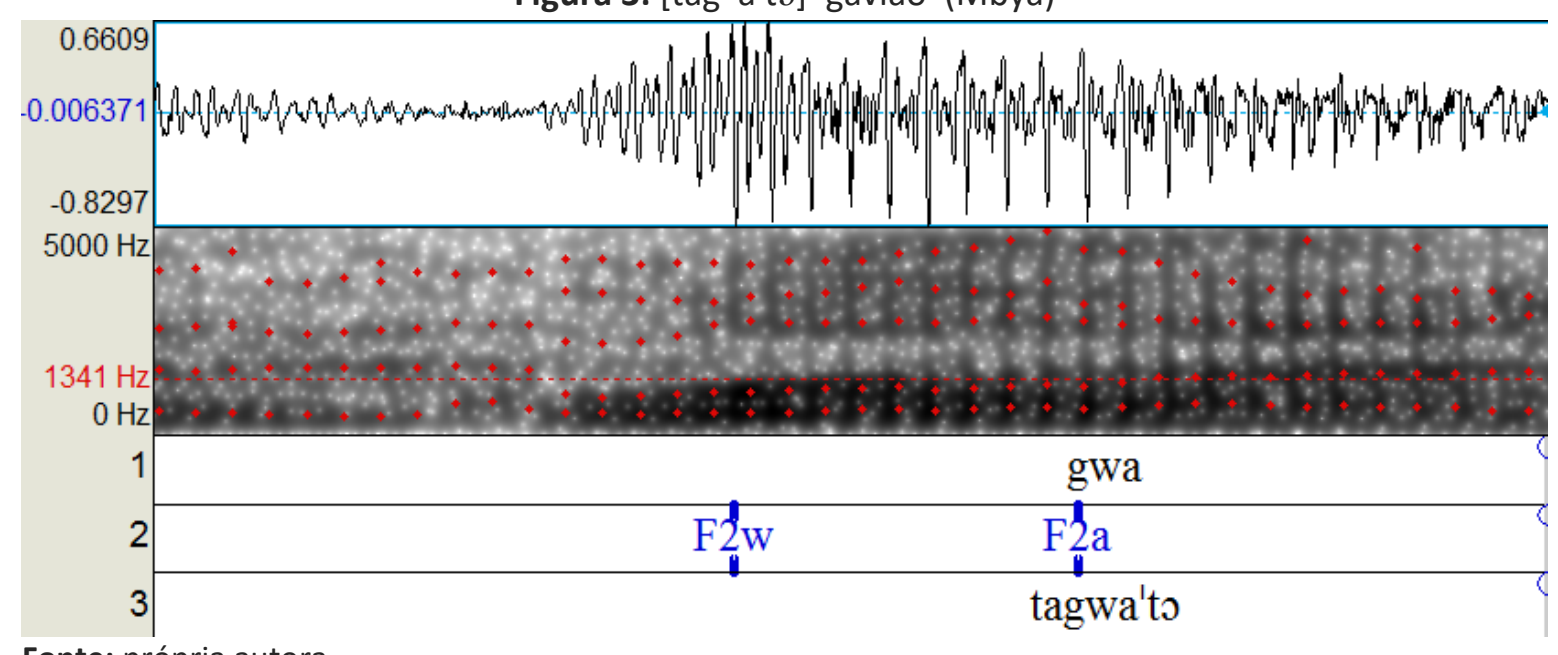

Fonte: própria autora

Nessa produção, o valor de F2, na porção da aproximante [w], no ponto indicado na figura, é de $984 \mathrm{~Hz}$, e o $\mathrm{F} 2$ da vogal, no ponto indicado, é de $1136 \mathrm{~Hz}$, confirmando-se, também, o abaixamento de $\mathrm{F} 2$.

Abaixo, apresentam-se os ambientes de ocorrência e algumas produções com as oclusivas velares labializadas $\left[\mathrm{k}^{\mathrm{w}}\right]$ e $\left[\mathrm{g}^{\mathrm{w}}\right]$. Distinções entre as parcialidades são apontadas:

[ $\left.\mathrm{k}^{\mathrm{w}}\right]$ ocorre no ataque de sílabas iniciais, mediais e finais, antes de segmentos vocálicos orais e nasais, à exceção das vogais arredondadas, com as quais não co-ocorre, em sílabas tônicas e prétônicas:

\begin{tabular}{|c|c|}
\hline [kwãrãpẽ'pẽ] & 'abóbora moranga' \\
\hline$\left[d_{3} i^{\prime} k^{w} \varepsilon\right]$ & 'caldo, sopa' \\
\hline [î'k $\left.k^{w} \tilde{a}\right]$ & 'dedo dele' \\
\hline [i'kwa] & 'buraco' \\
\hline [ta'kwa] & 'bambu, taquara' \\
\hline [k'ara'i $\mathbf{i}]$ & 'sol' (Nhandewa/SP_PR e Mbyá) \\
\hline [kwara'hi] & 'sol' (Nhandeva/MS e Kaiowá/MS) \\
\hline
\end{tabular}

[gw] ocorre no ataque de sílabas iniciais, mediais e finais, antes de segmentos vocálicos orais, à exceção das vogais arredondadas, com as quais não co-ocorre, em sílabas tônicas e pré-tônicas:

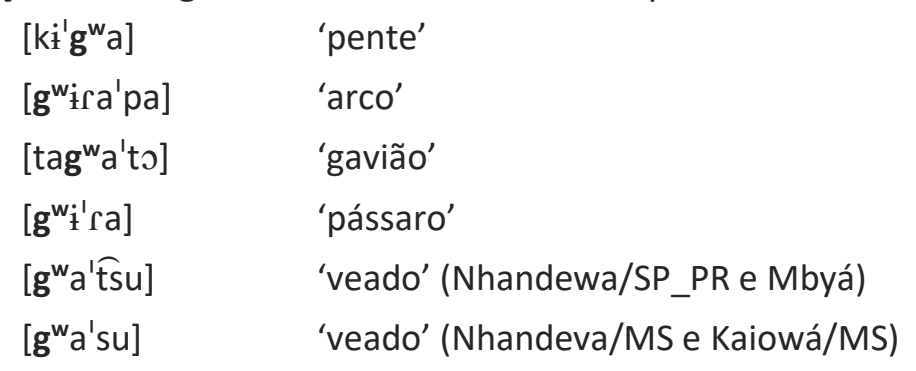

A seguir, passaremos a apresentar e refletir alguns processos fonológicos e morfofonológicos envolvendo as duas oclusivas velares labializadas. 


\section{Processos fonológicos e morfofonológicos envolvendo as oclusivas labializadas da língua Guarani}

Na língua Guarani, ainda que em casos raros, a oclusiva velar labializada /gw/ apresenta um contorno nasal em ambientes orais, sendo realizada como [ $\left.{ }^{\mathrm{g} g \mathrm{w}}\right]$. Observe-se, a seguir, na produção da palavra

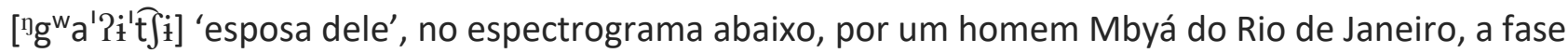
nasal homorgânica da labializada em posição inicial:

Figura 4: [ ${ }^{[} g^{w} a_{1} P i{ }^{\prime}$ tsìi] 'esposa dele' (Mbyá)

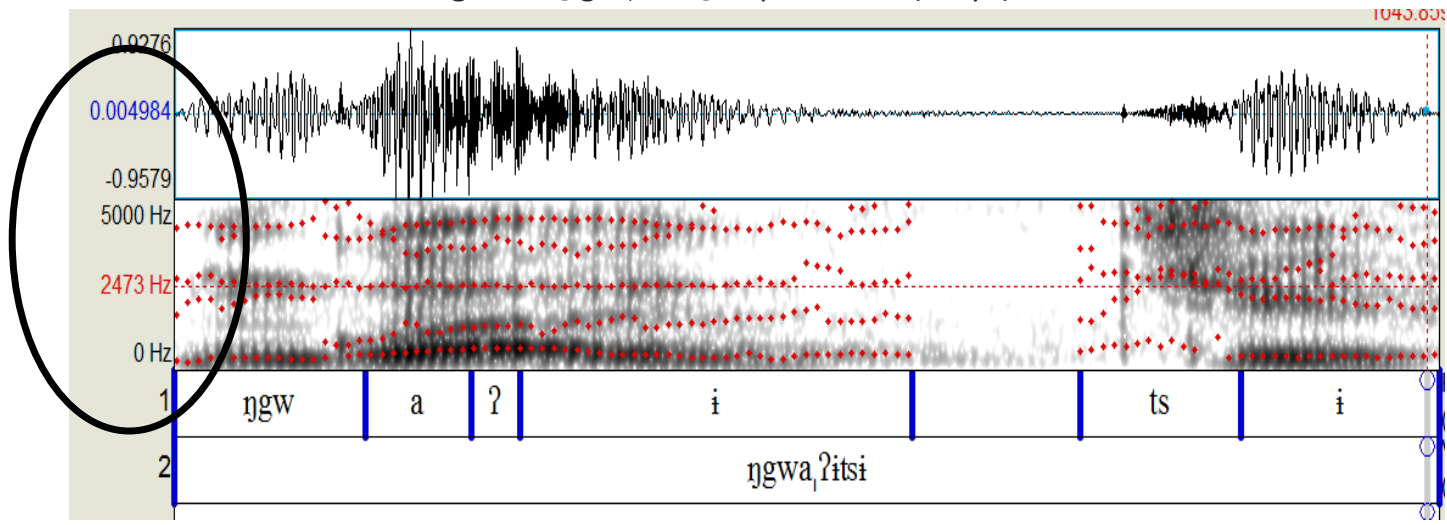

Fonte: própria autora

Esse som, quando em ambientes envolvendo espalhamento de nasalidade, pode perder a fase oral (observe-se a ausência da marca de oclusão no espectrograma abaixo), sendo realizada como plenamente nasal, a homorgânica [n], no dado /agwi'ñ̃/ 'azedo', por uma Mbyá. Neste dado, o gatilho para o espalhamento da nasalidade é vogal tônica final, que espalha a sua nasalidade para a esquerda:

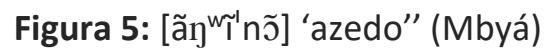

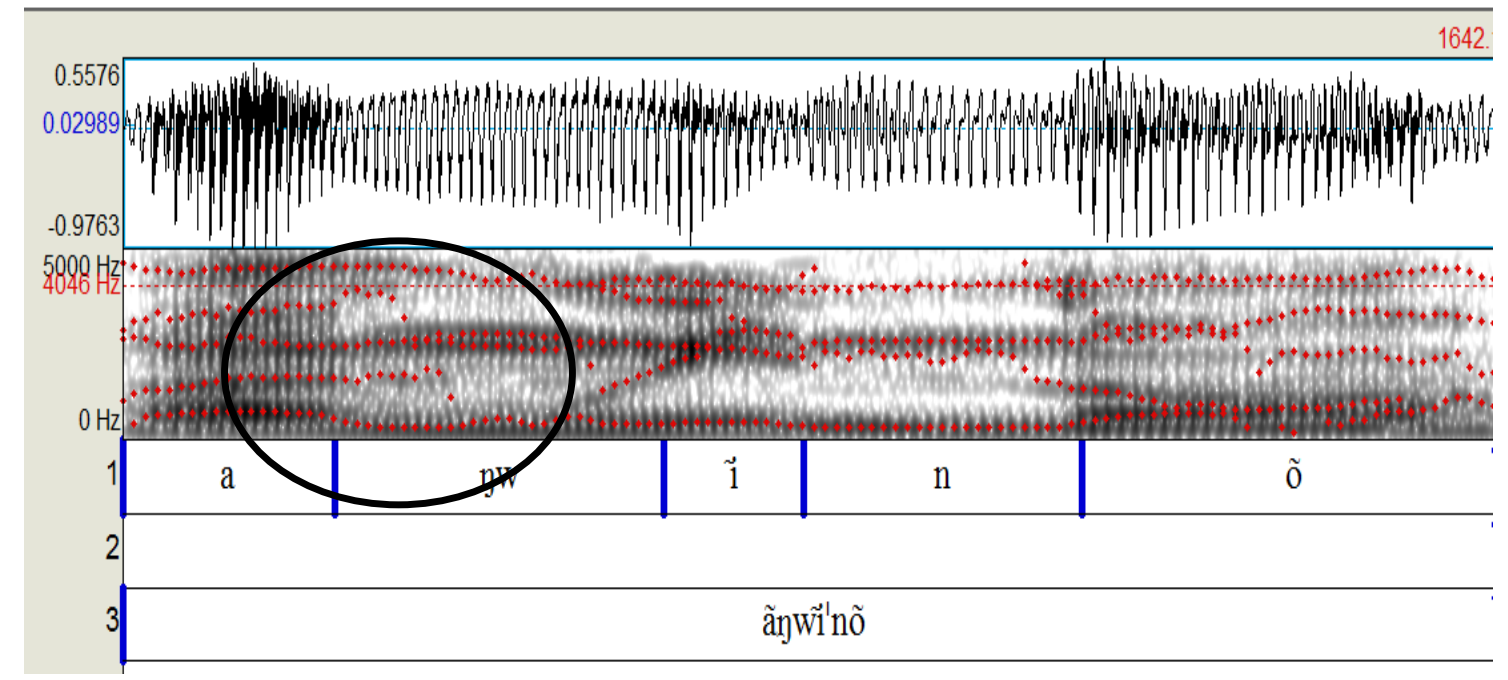

Fonte: própria autora

Observe-se, abaixo, no dado produzido por uma falante Kaiowá do Mato Grosso do Sul, o mesmo processo: 


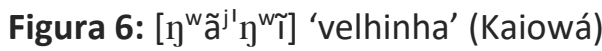

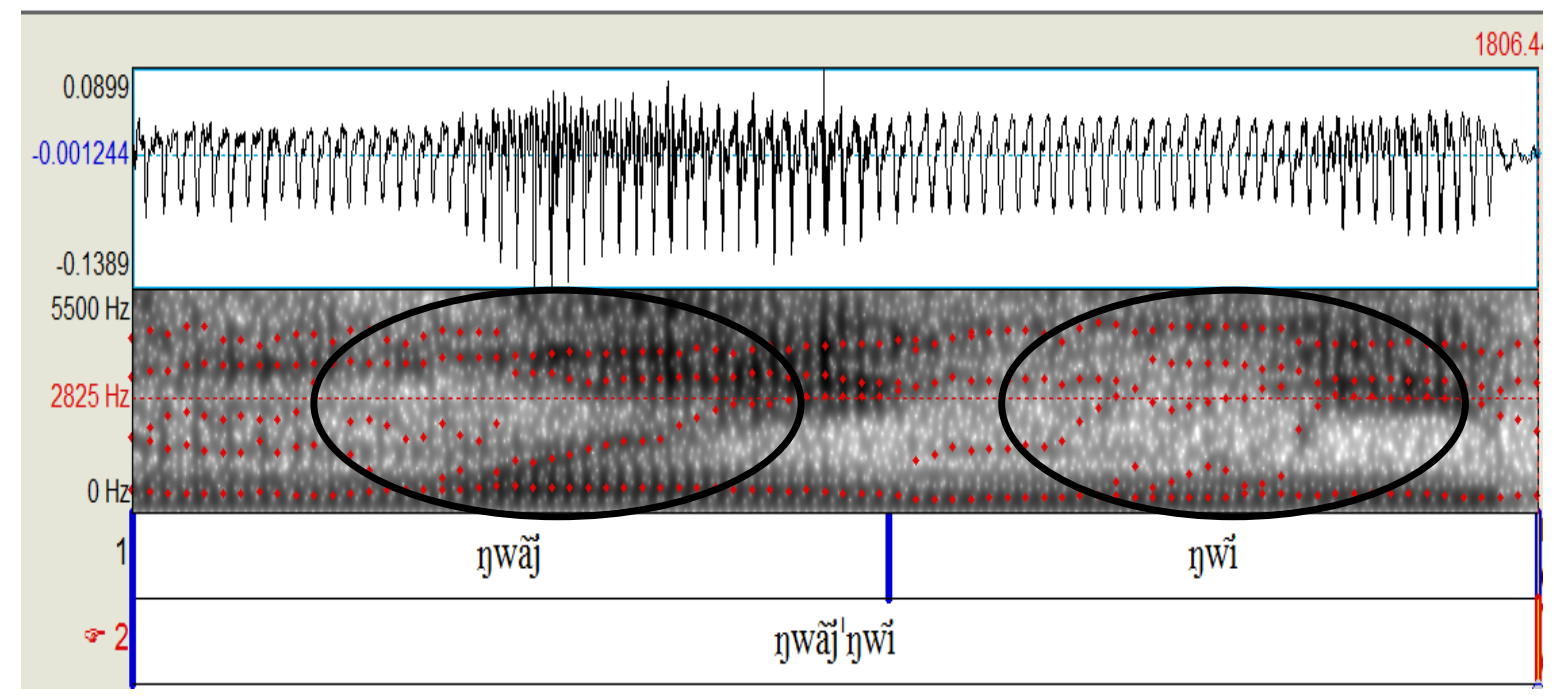

Fonte: própria autora

Há, na língua Guarani, uma distribuição complementar envolvendo as pré-nasais e as nasais plenas: a série de pré-nasais ocorre em ambientes orais e as nasais homorgânicas, em ambientes nos quais ocorre espalhamento de nasalidade, compondo uma série de soantes [-contínuas], na qual se insere $/ \mathrm{g}^{\mathrm{w}} /$ :

\begin{tabular}{|c|c|c|c|c|}
\hline \multicolumn{6}{|c|}{ Quadro 1: Soantes [- contínuas] } \\
\hline$/{ }^{\mathrm{m} b} /$ & $/{ }^{\mathrm{n}} \mathrm{d} /$ & $/ \mathrm{j} /$ & $/{ }^{\mathrm{g} g} /$ & $/ \mathrm{g}^{\mathrm{w}} /$ \\
{$\left[{ }^{\mathrm{m} b}\right]$} & {$\left[{ }^{\mathrm{d}} \mathrm{d}\right]$} & {$\left[{ }^{\mathrm{n}} \widehat{\mathrm{d}}\right][\mathrm{d} \widehat{3}]$} & {$\left[{ }^{\mathrm{g} g}\right]$} & {$\left[{ }^{\mathrm{g}} \mathrm{g}\right],\left[\mathrm{g}^{\mathrm{w}}\right]$} \\
{$[\mathrm{m}]$} & {$[\mathrm{n}]$} & {$[\mathrm{n}]$} &.-- & {$\left[\mathrm{\eta}^{\mathrm{w}}\right]$} \\
\hline
\end{tabular}

Soantes descontínuas: ocorrem antes de segmentos vocálicos orais, em sílabas tônicas e pré-tônicas.

Nasais Plenas: ocorrem antes de segmentos vocálicos nasais, em sílabas tônicas e prétônicas, à exceção da nasal velar [n], não verificada em nossos dados.

Observe-se que as únicas formas variantes que podem ocorrer eventualmente em prénasalização (ou, em alguns momentos apresentar uma pré-nasalização imperceptível aos ouvidos de um estrangeiro) são os que constituem segmentos complexos, ou africadas ou labializadas:

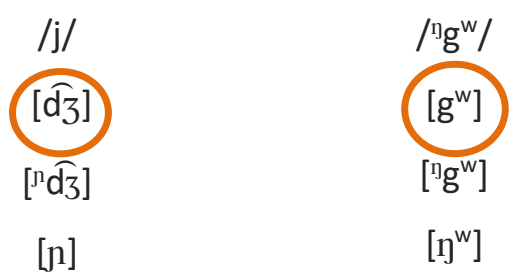

Este processo que nasaliza consoantes se estende a todas as soantes, ou seja, toda soante é alvo do processo de espalhamento nasal; só que, se ela for soante descontínua, o resultado é uma indiscutível consoante nasal plena; mas, se for a soante contínua, se nasalizada, se aproximam também muito de uma consoante nasal. Assim, um "w" nasalizado é, muitas vezes, confundido com 
um [m]; um " $\mathrm{c}$ " nasalizado, é muitas vezes confundido com um [n]; e um "j" nasalizado pode também se confundir com [n]. Em outras palavras, o contexto de nasalização é também um contexto de neutralização de oposições entre consoantes soantes contínuas e descontínuas (o que é, aliás, um argumento a favor de que o processo se dá na direção das orais para as nasais, e não o contrário).

A forma [ ${ }^{\mathrm{g}}{ }^{\mathrm{w}}$ ] não pode ser confundida com a realização do fonema $/ \mathrm{k}^{\mathrm{w}} /$ como [ $\left.{ }^{\mathrm{g}}{ }^{\mathrm{w}}\right]$, que é resultado de um processo morfofonológico. Nesses casos, há um espalhamento da nasalidade da vogal tônica nasal, à direita, que afeta o morfema. No exemplo abaixo, observe-se uma composição morfológica, na qual ocorrem dois processos fonológicos à direita: (01) vozeamento da labializada $\left(/ \mathrm{k}^{\mathrm{w}} />\left[\mathrm{g}^{\mathrm{w}}\right]\right)$ e $(02)$ espalhamento nasal a partir da vogal do radical ([ã]), o que faz com que a labializada receba um contorno nasal homorgânico, sendo realizada [ $\left.{ }^{\mathrm{g}} \mathrm{g}^{\mathrm{w}}\right]$ :

(1) [kã] 'osso' $+\left\{-k^{w} \varepsilon\right\}$ 'estado anterior' $=\left[k^{\prime} a^{\prime} g g^{w} \varepsilon\right]$ 'osso/o que era osso', 'ossada'.

Observe-se, abaixo, a realidade fonética do contorno nasal homorgânico da labializada $\left[\mathrm{g}^{\mathrm{w}}\right]$ na produção da palavra [kã'ngw $\varepsilon$ ] 'osso', por uma mulher Nhandewa de São Paulo:

Figura 7: [kã'ngw $\varepsilon$ ] 'osso' (Nhandewa)

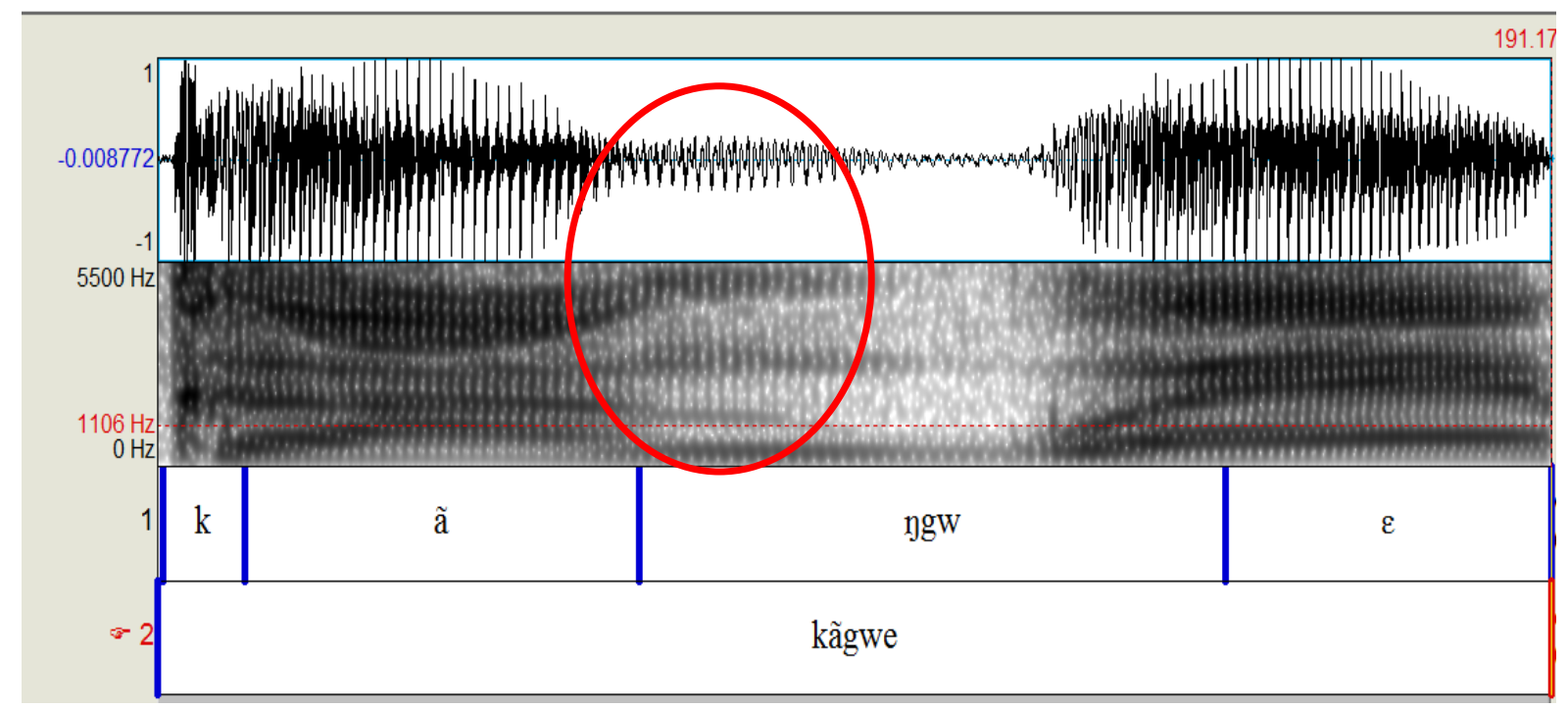

Fonte: própria autora

Nos processos morfofonológicos da língua Guarani, o espalhamento da nasalidade pode se dar tanto à esquerda quanto à direita. Inicialmente, pretendíamos encontrar uma explicação para o espalhamento da nasalidade à direita, que se desdobrava em um segundo processo, o vozeamento e pré-nasalização da obstruinte, como em [pẽ tĩ $]+\left\{k^{w} a\right]=\left[p e ̃ \tilde{t i}^{1}{ }^{1} g^{w} a\right]$, uma vez que as obstruintes surdas, à esquerda, permanecem transparentes ao espalhamento da nasalidade, isso no nível lexical. Observamos que esse processo ocorre com outros morfemas tônicos, o que nos levou a procurar uma possível generalização.

Os morfemas tônicos, apresentados a seguir, quando adjungidos a outras raízes, ou a outros morfemas, formam um novo sintagma nominal, assumindo o acento principal. As vogais desses morfemas permanecem tônicas e orais. Observemos que o processo se dá apenas com a obstruinte inicial do morfema, as vogais tônicas permanecem orais. Quando seguindo vogais orais, realizam-se 
como obstruintes surdas, e quando seguindo vogais nasais, realizam-se como obstruintes sonoras, com uma fase nasal inicial homorgânica. Esse mesmo comportamento pode ser observado com todas as oclusivas:

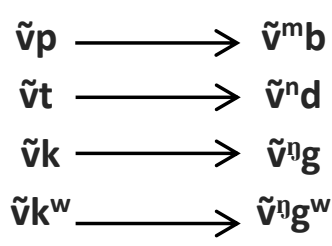

Observe-se o processo no morfema $\{$-ti $\}$ 'coletivo':

(2) [ava'ti] 'milho' $+\{$-ti $\}$ 'coletivo' $=[$ ava,ti'ti $]$ 'milharal'

(3) [nũ'ũ 'grama' + $\{$-tit $\}$ 'coletivo' = [nũ ũ'ndi $]$ 'plantação de grama'

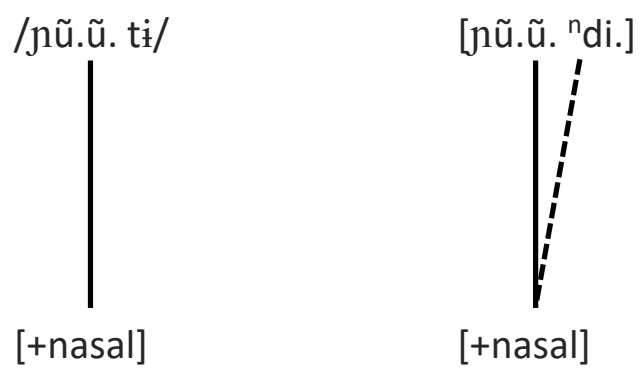

No dado [nẽpẽ, $\left.\tilde{t}^{1}{ }^{1} g^{w} a\right]$ 'seu cachimbo', a vogal nasal final tônica espalha nasalidade para à esquerda, com acento secundário, já que o acento primário, nesse caso, recai sobre uma vogal oral, fazendo com que a forma $\left\{{ }^{n} d \varepsilon-\right\}$ 'teu, tua' seja produzida $\{n \varepsilon-\}$, e para a direita, provoca dois processos: nasalização e vozeamento na obstruinte velar.

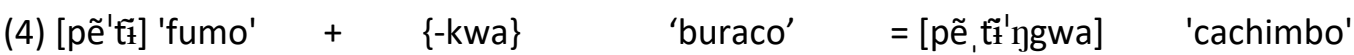
$\{$ nde-\} 'teu, tua' + [pẽ, trì'

AMBIENTE NASAL

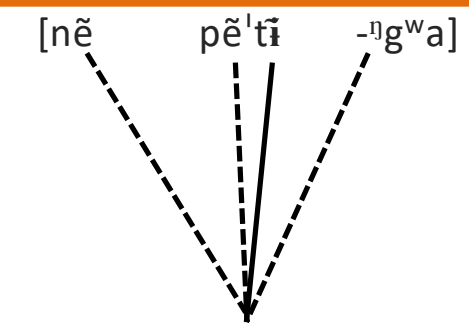

Em um ambiente oral, no entanto, o morfema $\left\{-\mathrm{k}^{\mathrm{w}} \mathrm{a}\right\}=$ 'buraco' não sofre alteração:

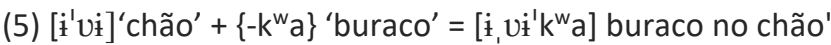


A seguir, mais alguns exemplos dessas ocorrências:

\section{\{katu\} 'intensif; bom, bonito'}

(6) $\left[\widehat{d}_{3} a^{\prime} h a\right]^{4}$ 'vamos' $\quad+\{k a ' t u\}$ 'intensif' $=[$ ḑza,haka'tu] 'vamos mesmo'

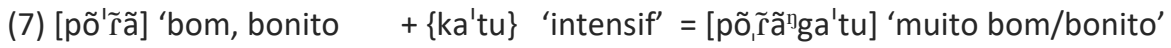

(8) [mõ'î] 'colocar' + \{ka'tu\} 'intensif' = [mõ̃inga'tu] 'guardar'

(9) [nẽ'ẽ] 'falar $\quad+\{k a ' t u\}$ 'intensif' $=$ [nẽ'ẽ̃

Quando o morfema causativo $\{\text {-mõ- }\}^{5}$ encontra uma obstruinte surda à direita, em ambiente oral, a obstruinte é vozeada e recebe uma margem nasal homorgânica. $\{$ mõ- $\}+/-k a ' r u /$ 'comer' = [mõ̃ga'ru] 'alimentar a'. O mesmo processo é observado no dado abaixo:

(10) $\{$ mõ- $\}$ 'causativo $+\left\{-\right.$ i'ko $^{\prime} \sim\{-$ 'ko $\}$ 'estar morar, viver, ser $=\left[\right.$ omõj $\left.{ }^{1 ! g} g 0\right]$ 'criou, fez'

É bastante importante considerar a variação entre os morfemas $\left\{-\right.$ i'ko $\left.^{\prime}\right\}$ $\{-$ 'ko\}, que são produzidos com e sem a vogal "i” (assilabificada na conjugação). Vejam-se os exemplos abaixo:

(11) [aj'ko] 'eu vivo, moro'

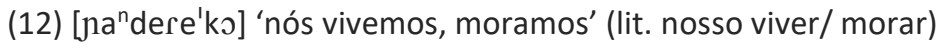

Quando é realizada a vogal "i" (assilabificada), como é o caso de[omõ̃' "go], a nasalização da vogal "i” é explicada pela entrada do morfema causativo \{mõ-\}, que causa o vozeamento e prénasalização na obstruinte surda /k/. Verificamos assim, a coerência e consistência do funcionamento da harmonia nasal no nível morfofonológico desta língua.

A seguir, outros exemplos desse mesmo processo envolvendo a realização do morfema causativo \{mõ-\} precedendo obstruintes surdas em ambientes orais:

(13) $\{$ mõ- $\}$ 'causativo' $+\left\{-i^{\prime} k \varepsilon\right\}$ 'entrar' $=$ [omõ $\left.\tilde{j}^{11} g \varepsilon\right]$ 'ele o fez entrar'

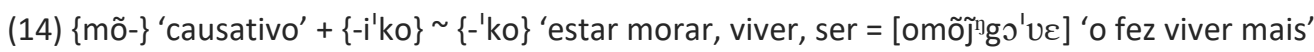

Outros morfemas confirmam o mesmo funcionamento do espalhamento nasal na língua Guarani:

$\left\{-k^{\mathrm{w}} \varepsilon\right\} \sim\left\{-{ }^{\mathrm{n}} \mathrm{g}^{\mathrm{w}} \varepsilon\right\}$ 'coletivo'
(15) [a'va]
'homem' $+\left\{-\mathrm{k}^{\mathrm{w}} \varepsilon\right\}$ 'coletivo' $=$
$\left[a, v a{ }^{\prime} k^{w} \varepsilon\right]$
'homens'
(16) [kũ'nã]
'mulher' $+\left\{-k^{\mathrm{w}} \varepsilon\right\}$ 'coletivo' $=$

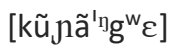
'mulheres'

$\left\{-\mathrm{k}^{\mathrm{w}} \varepsilon\right\} \sim\left\{{ }^{\mathrm{n}} \mathrm{g}^{\mathrm{w}} \varepsilon\right\}$ 'estado anterior'

(17) $\left[0^{\prime} P 0\right]$ 'carne' $+\left\{-\mathrm{k}^{\mathrm{w}} \varepsilon\right\}=\left[0,30^{\prime} \mathrm{k}^{\mathrm{w}} \varepsilon\right]$ 'carne alimento'

$\left[\mathrm{u}, \mathrm{su}\right.$ ro, $\left.2 \rho^{\prime} \mathrm{kw \varepsilon}\right]$ 'carne de galinha' (lit. carne que era da galinha)

(18) [pẽ] 'quebrar-se' $+\left\{-k^{w} \varepsilon\right\}=\left[p \tilde{e}^{\prime} \lg g^{w} \varepsilon\right]$ 'pedaço'

[i, vira pẽ'ngwe] 'tora' (lit. pedaço que era da árvore)

(19) $[-\mathrm{t} \varepsilon]$ 'corpo' $+\left\{-\mathrm{k}^{\mathrm{w}} \varepsilon\right\}=\left[\mathrm{t \varepsilon}^{\prime} \mathrm{k}^{\mathrm{w}} \varepsilon\right]$ 'defunto' (lit. o que era corpo)

\footnotetext{
${ }^{4}$ Essa é a forma utilizada pelos Nhandeva/MS e Kaiowá/MS. Os Mbyá e os Nhandeva/SP_PR utilizam a forma [dुza'a] ' vamos'

${ }^{5}$ Varia com $\{-\mathrm{mbo}-\}$
} 
$\left\{-\mathrm{k}^{\mathrm{w}} \varepsilon\right\} \sim\left\{-{ }^{\mathrm{n}} \mathrm{w}^{\mathrm{w}} \varepsilon\right\}$ 'atributivo'

(20) [ipõ'rã] 'ela /beleza $+\left\{-k^{w} \varepsilon\right\}=\left[i p o ̃, r a I^{\prime}{ }^{n} g^{w} \varepsilon\right]$ 'a beleza dela'

(21) [i,vate'kwe] 'o que é alto'

\section{$\left\{-k^{\mathrm{w}} \varepsilon\right\} \sim\left\{-{ }^{-1} \mathrm{~g}^{\mathrm{w}} \varepsilon\right\}$ 'passado'}

(22) $\left[\mathrm{va}^{\prime} \mathrm{P} \varepsilon\right]$ 'nominalizador' $+\left\{-\mathrm{k}^{\mathrm{w}} \varepsilon\right\}=+\left[\mathrm{va}, \varepsilon^{\prime} \mathrm{k}^{\mathrm{w}} \varepsilon\right]=$ 'o que era/foi'

(23) [oo va, $1 \varepsilon^{\prime} k^{w} \varepsilon$ te,tã ka'ti] 'foi para a cidade'

Observe-se que para formar o futuro do pretérito, o Guarani utiliza o morfema $\{-\tilde{r} a ̃\}$ 'futuro' $+\left\{-k^{\mathrm{w}} \varepsilon\right]$ 'passado', o que resulta na forma: $\left\{-\tilde{r} \tilde{a}^{1} \mathrm{~g} g w \varepsilon\right\}$ :

(24) [ha'?ع õmã'ñ̃ ] 'ele morreu'

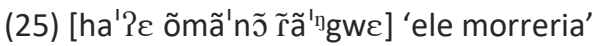

\section{$\{-$ ti $\} \sim\left\{{ }^{\text {nd }}\right.$ di $\}$ Coletivo}

(26) [ava'ti] 'milho' + $\{$-ti $\}$ 'coletivo' = [ava'titi] 'milharal'

(27) [nũ'ũ] 'grama'+ $\{-\mathrm{tị}\}$ 'coletivo' = [nũ'ũn dì] 'plantação de grama'

\section{Aspecto completivo $\{-$ pa $\} \sim\{-$ ma $\}$}

(28) $[$ oka'ru] 'comeram $+\{-$ pa $\}$ 'complet $=[$ oka,su'pa] 'comeram tudo'

(29) [õmã'ñ̃] 'morreram $+\{-$ pa $\}$ 'complet $=\left[\right.$ õmã,n $\left.\tilde{I}^{\prime m} \mathrm{ba}\right]$ 'morream todos'

\section{Algumas Considerações Finais}

Os fonemas labializados $/ \mathrm{k}^{\mathrm{w}} / \mathrm{e} / \mathrm{g}^{\mathrm{w}} /$, portanto, operam no jogo de oposição sistemática da língua Guarani: $/ \mathrm{k}^{\mathrm{w}} /$ pertence à classe das obstruintes [-estridentes] e $/ \mathrm{g}^{\mathrm{w}} /$, à classe das soantes [contínuas]. Os processos que as envolvem demonstram que a harmonia nasal é operante e é coerente nos processos fonológicos e também nos processos morfofonológicos, tendo como objetivo manter uma oposição funcional do seu sistema, a grande oposição entre obstruintes e soantes (veja o quadro fonológico abaixo, proposto para a língua Guarani).

Quadro 2: Sistema Fonológico do Guarani no Brasil (unificado das 4 parcialidades) ${ }^{6}$

\begin{tabular}{|c|c|c|c|c|c|c|c|}
\hline & & \multirow{3}{*}{ Labiais } & \multirow{2}{*}{\multicolumn{2}{|c|}{ Coronais }} & \multirow{2}{*}{\multicolumn{2}{|c|}{ Dorsais }} & \multirow{3}{*}{ Laríngeas } \\
\hline & & & & & & & \\
\hline & & & [+ ant] & {$[-$ ant $]$} & [-lab] & [+lab] & \\
\hline \multirow{2}{*}{ Obstruintes } & [- estridentes] & $\mathrm{p}$ & $\mathrm{t}$ & & k & $k^{w}$ & $?$ \\
\hline & [+ estridentes] & & $\widehat{t s} \sim s$ & $\widehat{\mathrm{t}} \sim \int$ & & & \\
\hline \multirow{2}{*}{ Soantes } & [- contínuas] & $\mathrm{mb}_{\mathrm{b}}$ & ${ }^{n} d$ & & "g & $\mathrm{ggw}^{\mathrm{w}}$ & \\
\hline & [+ contínuas] & $v$ & r & j & \multicolumn{2}{|c|}{ щ } & fi \\
\hline
\end{tabular}

${ }^{6}$ Observe-se que a única distinção no quadro diz respeito à produção das fricativas pelas parcialidades do Mato Grosso do Sul nos lugares em que as outras parcialidades produzem sons africados respectivamente. A função na oposição do sistema, entretanto, permanece a mesma. 


\section{Referências}

BOERSMA, P.; WEENINK, D. Praat Software. version 6.0.28. Disponível em:<http://www.fon.hum.uva.nl/ praat/>. Acesso em: 15 julho, 2017.

COSTA, C. P. G. Nhandewa Aywu: fonologia do Nhandewa-Guarani. Campinas/SP: Curt Nimeundajú; Vitória da Conquista, BA: Edições Uesb, 2010.

ELÍAS-ULLOA, J. A. An acoustic phonetics of Shipibo-Conibo (Pano), an endangered Amazonian language: a new approach to documenting linguistic data. Lewiston: Edwin Mellen Press, 2010.

IVO, I. P. Características fonéticas e estatuto fonológico de fricativas e africadas no Guarani-Mbyá.2014. Dissertação (Mestrado em Linguística), Instituto de Estudos da Linguagem, Universidade Estadual de Campinas, Campinas, SP, 2014.

IVO, I. P. Características Fonéticas e Fonologia do Guarani no Brasil. 2018. Tese (Doutorado em Linguística), Instituto de Estudos da Linguagem, Universidade Estadual de Campinas, Campinas, SP, 2018.

LADEFOGED, P.; MADDIESON, I. The Sounds of the World's Languages. Oxford: Blackwell Publishers, 1996.

MELIÁ, B. La lengua Guaraní del Paraguay: historia, sociedad y literatura. Madrid: Editorial Mapfre, 1992.

SCHADEN, E. Aspectos Fundamentais da Cultura Guarani. 3 ed. São Paulo: EDU/EDUSP, 1974. 